\title{
Polio vaccines exonerated
}

Robin A. Weiss

\section{One theory about the origin of the AIDS pandemic is that the virus responsible, HIV, was transmitted to humans from chimpanzees through contaminated polio vaccine. That theory fails some crucial tests.}

V accine manufacturers need to be ever vigilant lest their products become unwittingly contaminated by microbes lurking in the source materials used to make vaccines ${ }^{1}$. It was with such a possibility in mind that in 1999 Edward Hooper ${ }^{2}$ promulgated a startling theory about how the human immunodeficiency virus type 1 (HIV-1) first came to infect humans. Hooper proposed that early batches of live oral polio vaccine (OPV), supposedly grown in chimpanzee kidney cell cultures at the Wistar Institute, Philadelphia, and tested in Africa, became contaminated with a chimpanzee virus that was able to infect its new host - with lethal consequences.

Three brief papers ${ }^{3-5}$, beginning on page 1045 of this issue, bring in a 'not guilty' verdict on OPV. Tests by Blancou et al. ${ }^{3}$ and Berry et al. ${ }^{4}$ on early OPV stocks prepared at the Wistar Institute in the 1950s show that they were propagated in the kidney cells of rhesus monkeys, and that they lack nucleic-acid sequences related to either HIV or chimpanzees. And Rambaut and colleagues' evolutionary analysis ${ }^{5}$ of HIV-1 subtypes from the Democratic Republic of Congo (Zaire) indicates that the common ancestor to HIV-1 group $\mathrm{M}$, which gave rise to the pandemic strains, was present in a human host long before the first OPV field trials were conducted in the Congo during the late 1950s.

The idea that HIV might have been introduced to humans through contaminated polio vaccines has been around a long time. I first learned about it from an antivivisectionist tract circulated in 1987. The theory became notorious through Tom Curtis's article $^{6}$ in Rolling Stone in 1992, which proposed that HIV came from a simian immunodeficiency virus of African green monkeys $\left(\mathrm{SIV}_{\mathrm{AGM}}\right)$. By 1963, production of OPV had switched from using cells from Asian macaques to those from African green monkeys, following the discovery of another virus - simian vacuolating virus 40 - as a contaminant in macaque tissue $e^{1,7}$. Twentyfive years later, many African green monkeys were found to harbour SIV $_{\mathrm{AGM}}$, necessitating screening for this virus or use of human cell substrates in vaccine preparation.

But SIV $_{\mathrm{AGM}}$ is only distantly related to HIV-1, and cannot have been its precursor. The closest known animal virus to HIV-1 is SIV $_{\mathrm{CPZ}}$ of chimpanzees; in fact, the three

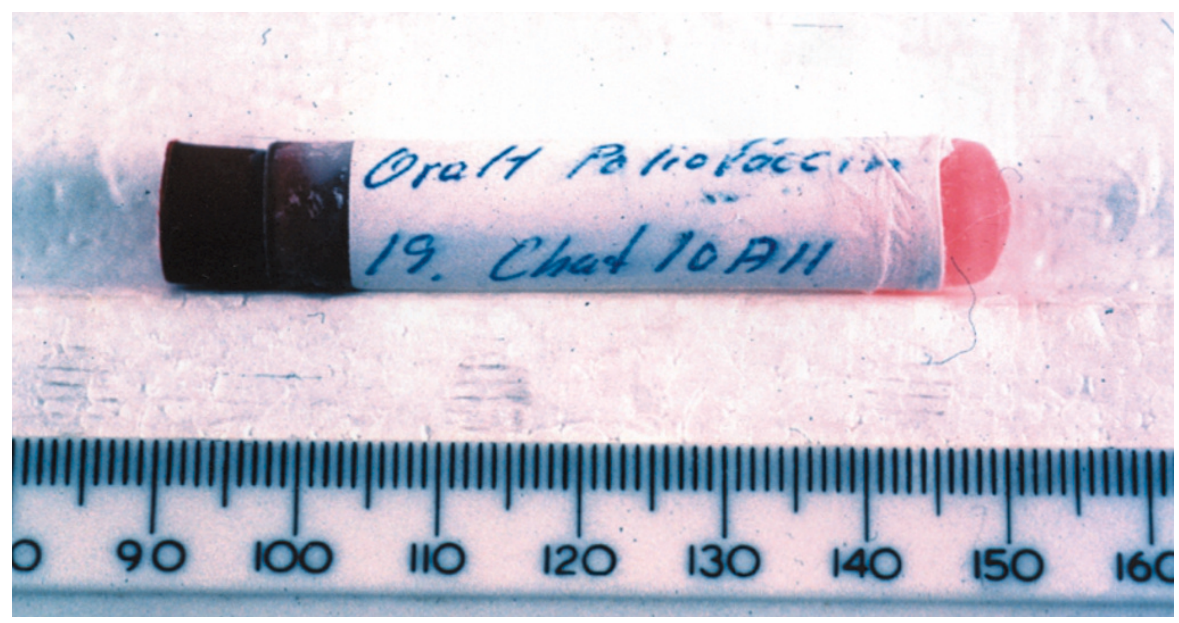

Figure 1 An original vial of CHAT 10A-11 oral polio vaccine (OPV). The vial was found at the National Institute for Biological Standards and Control, Potters Bar, UK. New tests show that the vaccine was prepared from the tissue of rhesus macaques, not of chimpanzees as required by the OPV-transmission hypothesis. (Photo courtesy of Harvey Holmes ${ }^{4}$.)

main groups of HIV-1, named $\mathrm{M}, \mathrm{N}$ and $\mathrm{O}$, differ from each other as much as they differ from $\operatorname{SIV}_{\mathrm{CPZ}}$, suggesting that there were at least three separate instances of cross-species transmission ${ }^{8}$. So if the OPV hypothesis on the origin of HIV were to remain plausible, the use of chimpanzee kidneys for OPV propagation had to be invoked ${ }^{2}$. Yet there is no documentation that chimpanzees were ever used for this purpose and, along with a paper simultaneously published in Science ${ }^{9}$, these new reports ${ }^{3-5}$ dismiss what reasonable conjecture existed.

From the sensitive and specific forensic DNA tests based on the polymerase chain reaction, it is clear that the cellular substrate for the early OPV batches was macaque tissue. This has been determined by three independent laboratories ${ }^{3,9}$ in samples made available by the Wistar Institute, which included the OPV batch (designated CHAT 13) used in Léopoldville (Kinshasa) between 1957 and 1959.

The OPV batch that Hooper ${ }^{2}$ considered to be under most suspicion, however, was CHAT 10A-11, which was also tested in Belgium's African colonies in the late 1950s. This batch was not available from the Wistar, but an original vial of the batch was found at Britain's National Institute for Biological Standards and Control (Fig. 1), and the new tests show that it was prepared from rhesus-macaque cells ${ }^{4}$. Further tests showed that these batches contained type-1 polio- virus only, as originally recorded for CHAT vaccines. There is no reason to doubt their authenticity.

Last year, Korber and colleagues ${ }^{10}$ extrapolated the timing of the origin of HIV-1 group $M$ back to a single viral ancestor in 1931, give or take about 12 years for $95 \%$ confidence limits. Because this calendar of events obviously pre-dated the OPV trials, in the revised version of his book ${ }^{2}$ Hooper suggested that group $\mathrm{M}$ first began to diverge in chimpanzees, and that there were then several independent transfers of virus to humans via OPV. In that case, several OPV batches should bear evidence of their production in chimpanzee tissue, yet no such evidence has been found ${ }^{3,4,9}$. In any case, the data of Rambaut et al. ${ }^{5}$, and those described in a forthcoming paper by Sharp et al. ${ }^{11}$, indicate that Hooper's interpretation is vanishingly unlikely. Rambaut et al. re-analysed sequence data, reported last year ${ }^{12}$, on the complexity of Congolese HIV-1 group M isolates. The diversity of HIV-1 in the Congo appears to pre-date the evolutionary radiation or 'starburst' of the major virus subtypes that have since spread across the world. But the genetic sequences conform to a single origin, presumably 'patient zero', the first human to become infected.

Defenders of the OPV hypothesis hold that the alternative route of cross-species virus transfer, an accidental infection from a chimpanzee, seems equally unlikely. Most 
of today's human infections, however, have come from various animal sources within the past 10,000 years or so ${ }^{13}$, a split-second on the evolutionary timescale. So $\operatorname{SIV}_{\mathrm{CPZ}}$ may have infected humans on numerous occasions in human history without becoming firmly established in our species, rather like the Lassa fever and Ebola viruses. What may have helped HIV-1 group $M$ to take off epidemically could have been the use of non-sterile needles and syringes in Africa in the mid-twentieth century ${ }^{14}$. This mode of transmission is currently behind the explosive spread of HIV-1 in parts of Russia and China. So one can envisage the involvement of an unintended medical factor in the adaptation of HIV to humans after it had crossed species from chimpanzees.

The new data ${ }^{3-5,9}$ may not convince the hardened conspiracy theorist who thinks that contamination of OPV by chimpanzee virus was subsequently and deliberately covered up. But those of us who were formerly willing to give some credence to the OPV hypothesis will now consider that the matter has been laid to rest. One may expect to hear an argument that chimpanzee kidney cells could have been used locally in Africa to amplify the batches of OPV prepared at the Wistar Institute in macaque cells, and that it was these vaccine samples that became contaminated. But the facilities for this type of cell culture did not exist in the Congo in 1957-59; besides, the evolutionary analysis of HIV-1 group M contradicts such a view.

The irony is that these new studies would almost certainly not have been undertaken if Hooper ${ }^{2}$ had not called for the analysis of DNA in stored OPV stocks, on the suggestion of the late Bill Hamilton. So we owe Hooper and Hamilton a debt of gratitude for pressing the case for those tests. When the preliminary results of the investigations were announced at the Royal Society in London last September, Hooper nonetheless dismissed them as "irrelevant to the OPV hypothesis". But that simply isn't so on the contrary, some beautiful facts have destroyed an ugly theory.

Robin A. Weiss is in the Department of Immunology and Molecular Pathology, University College

London, 46 Cleveland Street, London WIT 4JF, UK. e-mail:r.weiss@ucl.ac.uk

\section{Weiss, R. A. Emerg. Infect. Dis. 7, 153-154 (2001).}

2. Hooper, E. The River: A Journey Back to the Source of HIV and AIDS (Penguin, London, 1999; revised edn, 2000).

3. Blancou, P. et al. Nature 410, 1045-1046 (2001).

4. Berry, N. et al. Nature 410, 1046-1047 (2001).

5. Rambaut, A., Robertson, D. L., Pybus, O. G., Peeters, M. \& Holmes, E. C. Nature 410, 1047-1048 (2001).

6. Curtis, T. Rolling Stone 54-60, 106, 108 (19 March 1992).

7. Sweet, B. H. \& Hilleman, M. R. Proc. Soc. Exp. Biol. Med. 105, $420-427$ (1960).

8. Gao, F. et al. Nature 397, 436-441 (1999).

9. Poinar, H., Kuch, M. \& Pääbo, S. Science 292, 743-744 (2001).

10. Korber, B. et al. Science 288, 1789-1796 (2000).

11. Sharp, P. et al. Phil. Trans. R. Soc. Lond. B (in the press).

12.Vidal, N. et al. J. Virol. 74, 10498-10507 (2000).

13. Diamond, J. Guns, Germs and Steel (Vintage, London, 1998).

14. Marx, P. A., Alcabes, P. G. \& Drucker, E. Phil. Trans. R. Soc.

Lond. $B$ (in the press).

\section{Palaeontology \\ Ruffling feathers}

Hans-Dieter Sues

The evolution of feathers and flight were generally thought to be inextricably linked. But new fossils from China show that feathers pre-dated the origin of flight and of birds.

0 ne of the liveliest debates in palaeontology has concerned the origin of birds. There is now overwhelming anatomical evidence that birds evolved from small predatory dinosaurs known as theropods, and that the two groups are linked by a remarkable series of transitional forms ${ }^{1}$. Most palaeontologists accept this evidence. Only a small (if vocal) group continues to argue that birds have no close relationship to dinosaurs ${ }^{2}$.

Feathers are the most distinctive attribute of living birds. Traditionally, their evolution has been linked to the origin of flight ${ }^{2}$, but there have always been a few dissenting opinions $^{3,4}$. Two new studies, one published last month ${ }^{5}$ and the other in this issue ${ }^{6}$, now confirm that true feathers already existed in the non-flying dinosaurian relatives of birds and thus pre-dated the origin of birds and avian flight.

In recent years, there have been several reports of feathers and feather-like integumentary structures in various non-avian theropod dinosaurs from the Yixian Formation of Liaoning province in northeastern China $^{7-9}$. The Yixian Formation is of Early Cretaceous age (dated at 125 million years ago) and consists of a series of layered lake sediments and volcanic ashes. These deposits contain many remarkably preserved fossils of an amazing array of terrestrial, flying and aquatic animals. The fine-grained sedimentary rocks often retain traces of soft tissue and, in some cases, even identifiable gut contents.

One of the theropod dinosaurs from the Yixian Formation, Sinosauroptery $x^{7}$, showed unbranched fibre-like structures fringing the back of the head, neck, back and tail, which some researchers considered to be proto-feathers but others dismissed as

frayed internal fibres of collagen, a structural protein found in connective tissue. However, two other theropod dinosaurs from the same deposits, Caudipteryx and Protoarchaeopteryx $x^{8}$, undoubtedly possessed true feathers. In both, the body was covered by small feathers. Caudipteryx also had primary feathers attached to the second (longest) finger of its hands and sported a fan of feathers at the end of its tail. The tail of Protoarchaeopteryx bore symmetrical, vaned feathers in a fan-like arrangement. Opponents of the theropod-bird connection have suggested that Caudipteryx was actually a flightless $\operatorname{bird}^{10}$, but this claim is not supported by its skeletal structure.

The critics also noted that no feathers were known in dromaeosaurs, which share scores of derived skeletal features with early birds and thus are generally considered to be their closest relatives ${ }^{11}$. Dromaeosaurs were a group of small- to medium-sized, non-avian theropods, which include Velociraptor, the reptilian villain in the blockbuster movie Jurassic Park. They were especially characterized by the presence of a greatly enlarged claw on the second toe of the foot. Dromaeosaurs had long arms and long, grasping hands, but their forelimbs were not modified into wings.

In a report published last month, Xu et $a l .{ }^{5}$ documented the presence of compound filamentous integumentary structures in the somewhat scattered but well preserved remains of the type specimen of the dromaeosaur Sinornithosaurus millenii ${ }^{9}$ from the Yixian Formation. These structures exhibit two kinds of feather-like branching: filaments joined in a basal tuft, and several filaments joined at their bases in series along a central filament. What makes them particularly remarkable is their close correspondence to transitional stages II and IIIA predicted by a developmental model ${ }^{12}$ for the evolutionary origin of feathers in birds (Fig. 1).

In the second of the new papers, Ji et al. ${ }^{6}$ (page 1084 of this issue) report on the latest remarkable find from the Yixian Formation - a nearly complete, articulated skeleton of an unidentified dromaeosaur, most of the body of which is densely covered with feather-like structures. The complex filamentous structures on the arms and tail of the new fossil are especially striking. Most of them exhibit a radiating pattern of filaments originating from a single point. The structures on the arms appear to show a herring-bone pattern around a central stem, which is similar to bird feathers with their central rachis and serially attached barbs. Feathers are the only kind of covering found on living vertebrates that shows such a branching structure. So Ji et al. ${ }^{6}$ explicitly equate the filamentous structures of the new dromaeosaur to the feathers of birds.

The exceptionally preserved fossils from 